\title{
Typing of human isolates of Streptococcus agalactiae (group B streptococcus, GBS) strains from Zimbabwe
}

\author{
SYLVESTER R. MOYO, JOHAN A. MAELAND* and KÅRE BERGH* \\ Department of Medical Microbiology, University of Zimbabwe, Harare, Zimbabwe and * Department of \\ Microbiology, Norwegian University of Science and Technology (NTNU), Trondheim, Norway
}

\begin{abstract}
Serotyping and genotyping are important tools in epidemiological studies of group B streptococcal (GBS) infections, which are important diseases in man, particularly in newborns. In the present study, 241 GBS isolates from Zimbabwe, comprising 124 carrier isolates from pregnant women and 117 isolates from patients hospitalised for various diseases, were serotyped. Antibodies specific for the capsular polysaccharide antigens (CPAs) Ia, Ib and II-V and antibodies specific for the surface-localised proteins, $\mathrm{c}^{\alpha}, \mathrm{c}^{\beta}, \mathrm{R} 1, \mathbf{R 3}$ and $\mathrm{R} 4$ were used for serotyping. Strains of the CPA types Ia $(17 \%)$, III $(47.7 \%)$ and $V(23.2 \%)$ predominated. Of the various protein antigens, $c^{\alpha}$ and R4 were expressed with highest frequency, $\mathrm{c}^{\alpha}$ by $100 \%$ of the CPA type Ia strains and R4 by $92 \%$ of the CPA type III strains. The R3 protein occurred frequently (24\%), especially in type $\mathrm{V}$ strains $(\mathbf{8 4 \%} \%$ ). A total of 25 serovariants was detected in the strain collection with the variants $\mathrm{Ia}^{\alpha} \mathrm{c}^{\alpha}(\mathbf{1 6 \%})$, III/R4 $(43.5 \%)$ and $\mathrm{V} / \mathrm{c}^{\alpha}, \mathrm{R3}(\mathbf{1 4 . 1 \% )}$ occurring with the highest frequency. Serotype and subtype distribution of the carrier isolates were essentially similar to those of the disease-associated isolates. Genomic heterogeneity was demonstrated by pulsed-field gel electrophoresis of type III/R4 and type $\mathrm{V} / \mathrm{c}^{\alpha}$, R3 isolates, but to a much lesser extent than recorded with Norwegian strains. These results demonstrate that many variants of GBS occur in the Zimbabwean population. The data obtained may assist in the formulation of a possible future GBS vaccine for Zimbabwe and perhaps for other African countries.
\end{abstract}

\section{Introduction}

Streptococcus agalactiae (group B streptococcus, GBS) is a major cause of infection in man, particularly in neonates. While incidence rates of GBS diseases and GBS carrier rates are known in many industrialised countries, this is frequently not the case in developing countries - although some information is available [1]. In Zimbabwe, a carrier rate of $31 \%$ was described in 1990 on the basis of testing vaginal specimens [2] and, recently, a carrier rate of $31.6 \%$ was found in pregnant women in one area of Zimbabwe [3]. Accurate data concerning morbidity and mortality of GBS disease in Zimbabwe are not available. However, clinicians consider that GBS disease occurs with a high frequency in Harare, Zimbabwe (K. J. Nathoo, Harare, personal communication).

Received 30 Oct. 2001; revised version received 13 Feb. 2002; accepted 14 Feb. 2002.

Corresponding author: Professor J. A. Maeland (e-mail: Johan.Meland@medisin.ntnu.no).
Serotyping has for decades been of great importance in epidemiological studies of GBS disease and has more recently been supplemented by methods for molecular typing such as molecular fingerprinting and multi-locus enzyme genotyping. Serotyping is based primarily on the GBS capsular polysaccharide antigens (CPA) designated Ia, Ib and II-VIII [4]. Sometimes, the CPA typing is supplemented by identification of serosubtype markers, strain-variable protein antigens such as $\mathrm{c}^{\alpha}[5,6], \mathrm{c}^{\beta}$ [5], and the $\mathrm{R}$ proteins $\mathrm{R} 1-\mathrm{R} 4$ [7, 8]. In addition, a number of other GBS protein antigens have been described, some of which showed cross-reactivity with classical $\mathrm{R}$ protein antigens. These include proteins associated with type $\mathrm{V}$ strains [9-12] and protein Rib [13], which has been shown to cross-react with the R4 protein [14]. The CPAs and probably the protein antigens function as virulence factors [15] and these antigens are targets of protective antibodies [4].

The present study extends a previous study of GBS carrier strains isolated in Zimbabwe [3]. Isolates from pregnant Zimbabwean women and from hospitalised Zimbabwean patients colonised with GBS were sero- 
typed and sero-subtyped, and strains of two different serovariants were analysed by molecular fingerprinting.

\section{Materials and methods}

\section{Source of $G B S$}

GBS isolates from 117 pregnant women and from 124 patients hospitalised for various diseases, mostly infectious diseases, were included in the study. Due to inadequate data, patients with possible invasive GBS disease could not be identified with sufficient reliability. More than $90 \%$ of the pregnant women and hospitalised patients were black Zimbabweans. The pregnant women attended the Family and Child Health Department at Chinhoyi Hospital, Chinhoyi, Northern Zimbabwe for routine antenatal care checks and were selected for bacterial testing as described previously [3]. The hospitalised patients were from four regions of Zimbabwe (Harare, Bulawayo, Masvingo and Mashonaland Central; Bindura). For the purpose of this report, GBS isolates from the pregnant women and the hospitalised patients will be referred to as PW-GBS and HP-GBS, respectively.

\section{Culture and identification of GBS}

High vaginal and rectal swabs from pregnant women were cultured for GBS as described previously [3]. Specimens for diagnostic bacteriology from various sites in the hospitalised patients were cultured and bacteria were identified presumptively according to the procedures recommended by the Public Health Laboratories of Zimbabwe. Putative GBS from either of the population groups were cultured on blood agar plates and were identified by the CAMP test and by the Streptex reagent (Murex Biotech Limited, UK). Isolates were stored at $-80^{\circ} \mathrm{C}$ in Greave's medium and were transported to Trondheim, Norway for further analysis.

\section{Serotyping and sero-subtyping}

CPA typing was done by an indirect fluorescent antibody test (FAT) as described previously [16]. Briefly, the antisera used were raised against whole cells of reference or prototype strains for the various CPAs and were made CPA-specific by appropriate cross-absorption [16]. Smears were prepared from GBS which were cultured on blood agar plates and suspended in $0.15 \mathrm{M}$ phosphate-buffered saline (PBS), $\mathrm{pH}$ 7.2. The smears were air-dried, heat-fixed and incubated with rabbit antiserum appropriately diluted in PBS. The smears were washed with PBS and further incubated with FITC-conjugated anti-rabbit immunoglobulin (Dako A/S, Glostrup, Denmark). The slides were washed, mounted and read with a Nikon epifluorescence microscope, as described previously [16].

Detection of surface-localised protein antigen markers (subtyping) was done by dot-blotting, as described previously [17]. A rabbit antibody was used for the detection of the R1 protein [12], and monoclonal antibodies (MAbs) for detection of the protein antigens $\mathrm{c}^{\alpha}$ [6], $\mathrm{c}^{\beta}$ [18], R3 [19] and R4 [14]. Briefly, a 3- $\mu$ l volume of a bacterial suspension [17] was applied to strips of PVDF membranes (BioRad; Richmond, CA, USA) and air-dried. Non-specific sites were blocked by incubating for $30 \mathrm{~min}$ with defatted dried milk $3 \% \mathrm{w} / \mathrm{v}$ in PBS. Strips were washed twice in PBS with Tween $200.05 \% \mathrm{v} / \mathrm{v}$ (PBST), incubated for $90 \mathrm{~min}$ with the various antibodies at appropriate dilutions, washed and incubated with peroxidase-conjugated anti-immunoglobulin antibodies ( 1 in 1000; Dako A/S), washed and developed as described previously [17]. The reaction was stopped by immersion of the strips in water. The strips were read after drying and the results were recorded by matching against dot-blots probed with a nonsense MAb. Signalling was graded from 0 to $4+$. Positive and negative strains were included in all serotype and sero-subtype determinations.

\section{Macrorestriction analysis by $P F G E$}

Chromosomal DNA was prepared by modifications of previously described methods [20]. Briefly, one colony of GBS was inoculated and cultured in $20 \mathrm{ml}$ of ToddHewitt broth at $37^{\circ} \mathrm{C}$ overnight. The cells were pelleted by centrifugation and washed twice with $5 \mathrm{ml}$ of TEN buffer $(0.1 \mathrm{M}$ Tris-HCl, $0.1 \mathrm{M}$ EDTA, $0.15 \mathrm{M} \mathrm{NaCl}, \mathrm{pH}$ 7.5). The pellet was resuspended in $2 \mathrm{ml}$ of TEN and $50 \mu \mathrm{l}$ of this suspension were mixed with $200 \mu \mathrm{l}$ of TEN and $250 \mu \mathrm{l}$ of low-melting point agarose $2 \%$ in EC buffer (6 mM Tris-HCl, 0.1 M EDTA, $1 \mathrm{M} \mathrm{NaCl}$, Brij-58 0.5\%, $5 \mathrm{~mm}$ sodium desoxycholate, $17 \mathrm{mM} \mathrm{N}$ laurylsarcosine, $1 \mathrm{mM} \mathrm{MgCl}_{2}$ ), which had been heated and cooled to $58^{\circ} \mathrm{C}$. The mixture was pipetted into plug moulds and allowed to solidify. The plug moulds were placed into $3 \mathrm{ml}$ of EC buffer with the addition of $100 \mu \mathrm{l}$ of lysozyme $(20 \mathrm{mg} / \mathrm{ml}), 50 \mu \mathrm{l}$ of RNAase $(1 \mathrm{mg} / \mathrm{ml})$ and 50 units of mutanolysin (Sigma) and incubated at $37^{\circ} \mathrm{C}$ for $5 \mathrm{~h}$ with gentle shaking. The buffer was replaced with $4 \mathrm{ml}$ of ES buffer $(0.5 \mathrm{M}$ EDTA and $34 \mathrm{mM} \mathrm{N}$-laurylsarcosine) with proteinase $\mathrm{K}$ $2 \mathrm{mg}$ and incubation was performed overnight at $50^{\circ} \mathrm{C}$. The plugs were then washed four times for $1 \mathrm{~h}$ in TE buffer (10 mM Tris-HCl, $1 \mathrm{mM}$ EDTA) at room temperature with gentle shaking.

Slices of the plug mould were exposed to digestion with restriction endonuclease SmaI (20 U in $100 \mu \mathrm{l}$ of fresh reaction buffer; BioLabs, New England) for $4 \mathrm{~h}$ at $25^{\circ} \mathrm{C}$ in a heat block. Pulsed-field gel electrophoresis (PFGE) was performed with a CHEF XA Mapper (Bio$\mathrm{Rad})$ in $0.5 \times \mathrm{TBE}$ under the following electrophoretic conditions: agarose 1\% (Pulsed Field Certified Agarose, BioRad), $14^{\circ} \mathrm{C}, 6 \mathrm{~V} / \mathrm{cm}$, run time of $24 \mathrm{~h}$ and switch time 5-50 s (linear ramp). Gels were stained with ethidium bromide and visualised under UV illumination. Image capturing was performed with the 
Gel Doc 2000 Documentation System (BioRad Laboratories). Pulsotypes were compared and classified in dendrograms by means of the Jaccard coefficient with $2.5 \%$ band tolerance and the unweighted pair group method with arithmetic mean clustering methods provided by Molecular Analyst Fingerprinting DST Software version 1.6 (BioRad).

\section{Results}

\section{Serotyping}

The results of the CPA typing are shown in Table 1. Of 241 GBS isolates tested, 238 isolates could be serotyped with six anti-CPA reagents. GBS of CPA types Ia, III and V predominated. Together, strains of these CPA types comprised $88 \%$ of the isolates with type III strains amounting to nearly half of the isolates. NT strains and type Ib, II and IV strains occurred rarely. The proportionate distribution of strains of the various CPA types in the PW-GBS and HP-GBS was nearly the same.

Like the CPAs (Table 1), the strain-variable protein antigens were expressed with nearly the same frequency in the Zimbabwean PW-GBS and HP-GBS. The rates of expression of the proteins in the whole strain collection are shown in Table 2. The majority of strains $(64.3 \%)$ expressed only one of the proteins, $28.6 \%$ expressed more than one protein and $7 \%$ expressed none of them. $\mathrm{C}^{\alpha}$ and R4 occurred most often, each of them being expressed individually by $45.2 \%$ of the isolates and both by $1.2 \%$. Altogether, 221 (91.7\%) of the 241 strains expressed $c^{\alpha}, \mathrm{R} 4$ or both. R1 was expressed by only one of the isolates, whereas $\mathrm{R} 3$ was expressed by a quarter of them. $\mathrm{C}^{\beta}$ occurred comparatively rarely.

Table 3 shows the expression of the protein antigens in relation to the CPA types. Isolates of the various CPA types segregated into a variable number of subtypes ranging from two to six subtypes for CPA types Ia and $\mathrm{V}$, respectively. A total of 25 serovariants was detected.

Table 1. Distribution of capsular antigen types among disease-associated and carrier isolates of GBS from Zimbabwe

\begin{tabular}{lllr}
\hline & \multicolumn{2}{l}{ Number $(\%)$ of GBS isolates from } \\
\cline { 2 - 4 } Capsular & $\begin{array}{l}\text { hospitalised } \\
\text { antigen type }\end{array}$ & $\begin{array}{l}\text { pregnant } \\
\text { pomen }\end{array}$ & \multicolumn{1}{c}{ Total } \\
\hline Ia & $24(19.4)$ & $17(14.5)$ & $41(17.0)$ \\
Ib & $2(1.6)$ & $6(5.1)$ & $8(3.3)$ \\
II & $2(1.6)$ & $5(4.3)$ & $7(2.9)$ \\
III & $62(50.0)$ & $53(45.3)$ & $115(47.7)$ \\
IV & $5(4.0)$ & $6(5.1)$ & $11(4.6)$ \\
V & $28(22.6)$ & $28(23.9)$ & $56(23.2)$ \\
NT & $1(0.8)$ & $2(1.7)$ & $3(1.3)$ \\
Total & $124(100)$ & $117(100)$ & $241(100)$ \\
\hline
\end{tabular}

NT, not typable.
Table 2. Expression of various strain-variable protein antigens in 241 Zimbabwean GBS isolates

\begin{tabular}{lr}
\hline Antigen & Number (\%) of isolates \\
\hline $\mathrm{c}^{\alpha}$ & $112(46.5)$ \\
$\mathrm{c}^{\beta}$ & $28(11.6)$ \\
$\mathrm{R} 1$ & $1(0.4)$ \\
$\mathrm{R} 3$ & $58(24.0)$ \\
$\mathrm{R} 4$ & $112(46.5)$ \\
None & $17(7.0)$ \\
\hline
\end{tabular}

Table 3. Distribution of subtypes among GBS isolates of various capsular antigen types

\begin{tabular}{|c|c|c|c|}
\hline $\begin{array}{l}\text { Capsular antigen } \\
\text { type }\end{array}$ & $\mathrm{n}$ & $\begin{array}{l}\text { Subtype } \\
\text { designation }\end{array}$ & $\begin{array}{l}\text { Number }(\%)^{*} \\
\text { of isolates }\end{array}$ \\
\hline Ia & 41 & $\begin{array}{l}\mathrm{Ia} / \mathrm{a} \\
\mathrm{Ia} / \alpha, \beta\end{array}$ & $\begin{aligned} 38 & (93.0) \\
3 & (7.0)\end{aligned}$ \\
\hline $\mathrm{Ib}$ & 8 & $\begin{array}{l}\mathrm{Ib} / \mathrm{a} \\
\mathrm{Ib} / \alpha, \beta \\
\mathrm{Ib} / \alpha, \mathrm{R} 3\end{array}$ & $\begin{array}{l}3(37.5) \\
2(25.0) \\
3(37.5)\end{array}$ \\
\hline II & 7 & $\begin{array}{l}\text { II } \\
\text { II/ } \alpha, \beta \\
\text { II/R4 }\end{array}$ & $\begin{array}{ll}5 & (71.0) \\
1 & (14.5) \\
1 & (14.5)\end{array}$ \\
\hline III & 115 & & $\begin{array}{l}9(7.7) \\
1(0.9)\end{array}$ \\
\hline IV & 11 & $\begin{array}{l}\mathrm{III} / \mathrm{R} 4 \\
\mathrm{IV} \\
\mathrm{IV} / \alpha, \beta \\
\mathrm{IV} / \alpha, \beta, \mathrm{R} 3 \\
\mathrm{IV} / \alpha, \beta, \mathrm{R} 3, \mathrm{R} 4 \\
\mathrm{IV} / \mathrm{R} 3, \mathrm{R} 4\end{array}$ & $\begin{aligned} 105 & (91.4) \\
2 & (18.2) \\
2 & (18.2) \\
4 & (36.4) \\
1 & (9.0) \\
2 & (18.2)\end{aligned}$ \\
\hline $\mathrm{V}$ & 56 & $\begin{array}{l}\mathrm{V} / \alpha \\
\mathrm{V} / \alpha, \beta \\
\mathrm{V} / \alpha, \mathrm{R} 3 \\
\mathrm{~V} / \alpha, \beta, \mathrm{R} 3 \\
\mathrm{~V} / \alpha, \mathrm{R} 3, \mathrm{R} 4 \\
\mathrm{~V} / \beta, \mathrm{R} 3\end{array}$ & $\begin{aligned} 6 & (10.7) \\
3 & (5.4) \\
34 & (60.7) \\
9 & (16.0) \\
2 & (3.6) \\
2 & (3.6)\end{aligned}$ \\
\hline NT & 3 & $\begin{array}{l}\mathrm{NT} \\
\mathrm{NT} / \alpha, \beta, \mathrm{R} 3 \\
\mathrm{NT} / \mathrm{R} 4\end{array}$ & $\begin{array}{ll}1 & (33.3) \\
1 & (33.3) \\
1 & (33.3)\end{array}$ \\
\hline
\end{tabular}

${ }^{*}$ Calculated as percentage of total number of isolates of each capsular antigen type.

Strains of different CPA types expressed the proteins with highly variable frequencies. For instance, $\mathrm{c}^{\alpha}$ was expressed by all the type Ia isolates but not by any of the type III strains, whereas R4 was produced by nearly all $(91.4 \%)$ of the type III strains but not by any of the Ia strains. R3 occurred with high frequency $(83.9 \%)$ in the type $\mathrm{V}$ strains but rarely or not at all in isolates of other CPA types. $\mathrm{C}^{\beta}$, expressed by $11.6 \%$ of the isolates, occurred in strains of all the CPA types except in the type III strains. Thus, expression rates which varied from one protein to another and CPA-correlated expression rates were demonstrated.

\section{Genotyping of Zimbabwean GBS strains}

To investigate Zimbabwean GBS strains for heterogeneity at the genomic level, a total of 86 HP-GBS isolates was examined by PFGE: 59 serotype III/R4 strains and 27 serotype $\mathrm{V} / \mathrm{c}^{\alpha}, \mathrm{R} 3$ strains. With SmaI 
digestion of DNA, 7-12 fragments were regularly recorded, as seen in Fig. 1, which shows the banding pattern recorded for five type III/R4 strains with different patterns.

At a level of similarity of $80 \%$, the 59 type III/R4 isolates could be segregated into five groups with 1-53 isolates in each group (Fig. 2A). In the large group of 53 isolates, 26 isolates displayed $100 \%$ similarity. When the same criterion for similarity was applied for 27 type $\mathrm{V} / \mathrm{c}^{\alpha}$, R3 isolates, a larger degree of genomic heterogeneity was observed with 12 different groups with 1-8 isolates in each group (Fig. 2B). In the latter group seven isolates showed $100 \%$ similarity. The results obtained demonstrate genetic diversity of both the type III/R4 and the type $\mathrm{V} / \mathrm{c}^{\alpha}, \mathrm{R} 3$ isolates of the Zimbabwean GBS strain collection examined, but with greater genomic diversity of the latter serotype.

\section{Discussion}

The actual incidence of GBS disease in adults and neonates in Zimbabwe is not known, but we have reason to believe that the incidence is comparatively high. Also, the carrier rate of $31.6 \%$ in pregnant women in one area of the country was higher than found in some Western countries [21-23], and higher than the colonisation rate found in pregnant women in the Gambia [24] and some other African countries [1]. In

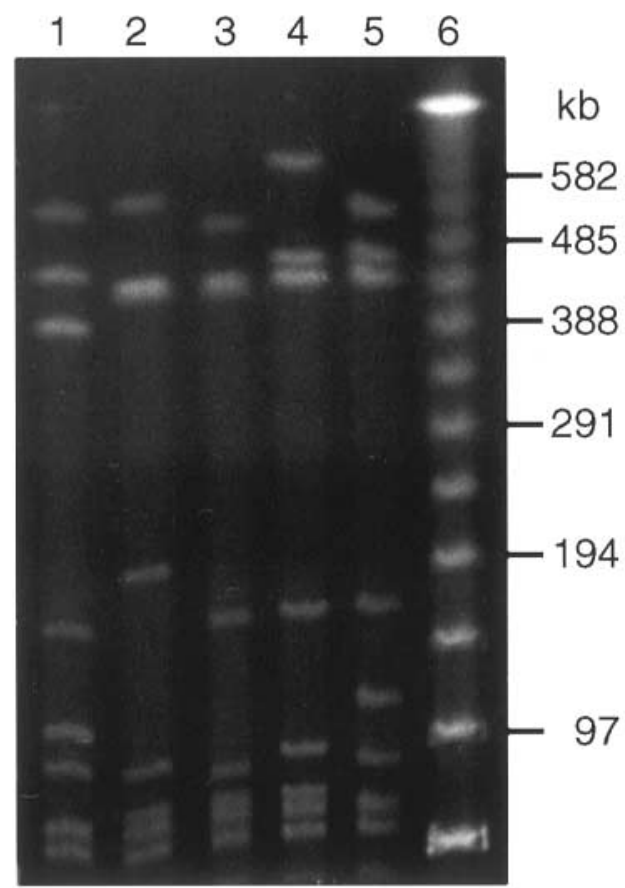

Fig. 1. SmaI macrorestriction pattern of Zimbabwean GBS type III isolates analysed by PFGE. The figure shows representatives of five different GBS genotypes. Lane 1, isolate no. 70; $\mathbf{2}$, isolate no. $84 ; \mathbf{3}$, isolate no. $139 ; \mathbf{4}$, isolate no. $214 ; \mathbf{5}$, isolate no. $232 ; \mathbf{6}$, molecular size markers.
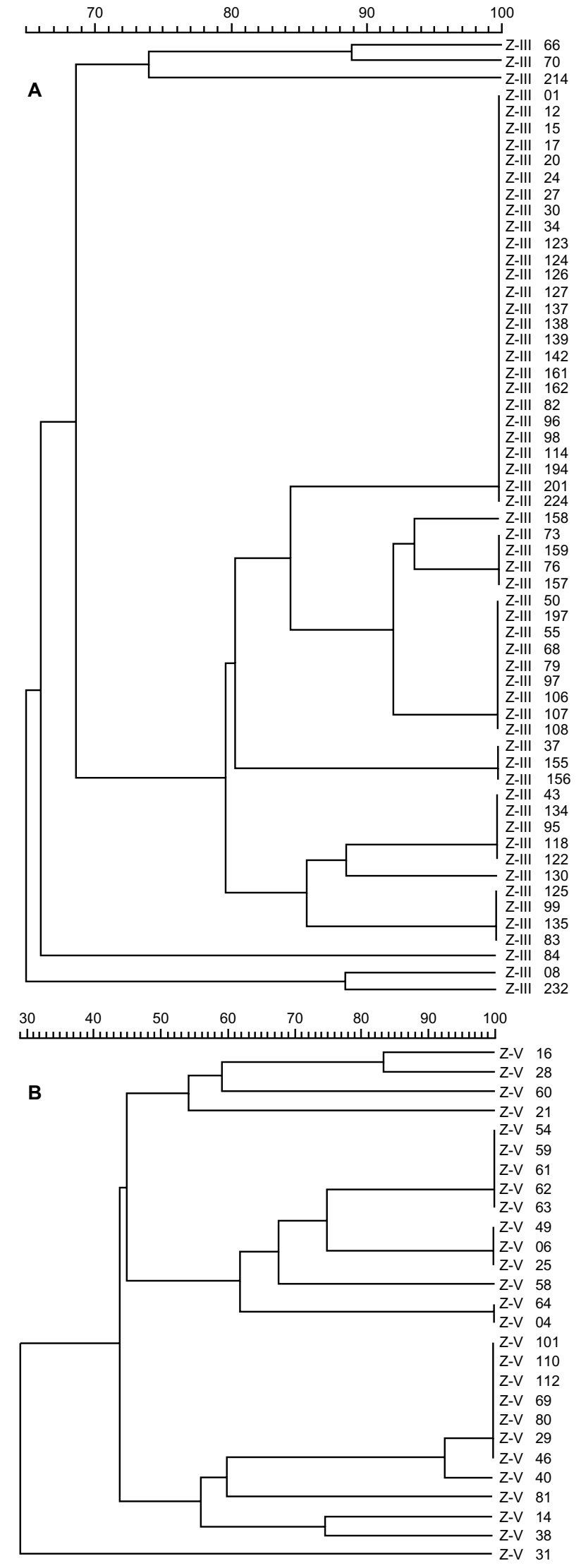

Fig. 2. Dendrograms based on Jaccard similarity coefficients from SmaI-generated macrorestriction patterns of Zimbabwean GBS isolates. The dendrogram was created by the unweighted pair group method with arithmetic averages. (A) Distribution of 59 type III/R4 GBS isolates. (B) Distribution of 27 type $\mathrm{V} / \mathrm{c}^{\alpha}, \mathrm{R} 3 \mathrm{GBS}$ isolates. 
the present study, 124 GBS carrier isolates from pregnant Zimbabwean women and 117 isolates which had colonised hospitalised patients were characterised by serotyping and, to a limited extent by PFGE, to unveil the extent of diversity among Zimbabwean GBS strains.

Of 241 Zimbabwean isolates examined, 238 could be classified by the use of antibodies that recognised the CPA antigens Ia-V. Thus, it appears that GBS of the CPA types VI, VII and VIII occur rarely if at all in the Zimbabwean population, which is different from other geographical areas such as Japan where GBS of the CPA types VI and VIII predominated [25]. Strains of the CPA types Ia (17.0\%), III (47.7\%) and V (23.2\%) predominated. When combined, these serotypes comprised $87.9 \%$ of the strain collection. Two or all three of these serotypes have also been prevalent among GBS isolates from other areas of the world [22, 26, 27], but not in a Gambian GBS collection which showed low frequency of type III and high frequency of type II and type V strains [24]. However, for most African countries GBS serotype distribution is not known. Over the last $10-15$ years, type V GBS strains have emerged with increasing frequency in several areas [28, 29], and this also seems to be the case in Zimbabwe, as type $\mathrm{V}$ strains amounted to as many as $23.2 \%$ of the isolates.

All the GBS protein antigens included in the testing, $\mathrm{c}^{\alpha}, \mathrm{c}^{\beta}, \mathrm{R} 1, \mathrm{R} 3$ and R4, were detected among the Zimbabwean GBS and these antigens permitted subtype determination of isolates of all six CPA types that we have identified. A total of 25 serovariants was identified. The distribution of the protein markers among the isolates of different CPA types showed similarities to the distribution in strain collections from other areas [26, 27] but with some differences. Thus, the R1 protein was detected in only 1 of 241 Zimbabwean isolates examined whereas this protein was expressed by $10 \%$ of Norwegian isolates, most frequently $(72 \%)$ by CPA type V strains [12]. The R3 protein, on the other hand, mostly expressed by type II strains in a Norwegian strain collection [19], was expressed by $84 \%$ of the Zimbabwean type $\mathrm{V}$ isolates. Thus, major differences in phenotypes exist between Norwegian and Zimbabwean type $\mathrm{V}$ strains. It is possible that R1 and R3 have similar functions when expressed by type V GBS strains. The $\mathrm{c}^{\alpha}$ or R4 proteins, rarely both, were each expressed by $46.5 \%$ of the Zimbabwean isolates, which seems to represent a very high rate of expression [27]. A number of isolates expressed more than one of the protein markers, in particular isolates of the serotypes IV and V. The results show that the combined $\mathrm{CPA}$ and protein antigen typing discriminated between phenotypic variants of GBS of African origin, as with GBS of European origin [27].

The distribution of GBS serotypes and subtypes among disease-associated strains, including some blood culture and CSF isolates, was nearly the same as that of vaginal carrier strains. Thus, a variety of serovariants of GBS are capable of colonising different body sites.

Several studies have described molecular fingerprinting results for GBS and have documented considerable genomic heterogeneity among strains of identical serotypes [20, 30-32]. This was also the case in the present study of Zimbabwean GBS strains in which analysis by PFGE was restricted to type III/R4 and type $\mathrm{V} / \mathrm{c}^{\alpha}, \mathrm{R} 3$ isolates. Both groups of isolates included several pulsotypes, with the type $\mathrm{V}$ strains exhibiting the highest degree of genomic heterogeneity. PFGE of 42 Norwegian type III/R4 strains with the same technique revealed 19 different pulsotypes (unpublished observations), consistent with much greater genomic diversity than found for Zimbabwean type III/R4 strains. Factors underlying this difference remain speculative but one factor of note is that the Norwegian isolates were collected from all over Norway, whereas the Zimbabwean isolates were collected from restricted areas of Zimbabwe. Among the Zimbabwean type III/R4 isolates, $44 \%$ belonged to the same pulsotype. These isolates probably represent a clonal lineage that is widely distributed in the Zimbabwean population.

Development of a GBS vaccine for the generation of immunity to prevent GBS disease has been in progress for years. CPA-protein conjugate vaccines have proved efficient in animal experiments and have attained clinical trials [4]. Knowledge of the distribution of GBS serotypes within the area is necessary to formulate an effective GBS vaccine for that area. In Zimbabwe, a vaccine containing type III and type V CPA could be effective in $c$. $70 \%$ of the population (Table 1) and by adding type Ia CPA, the vaccine could become effective in $80-85 \%$ of the population. The surface-localised protein markers of GBS harbour protective epitopes and have been considered potential candidates for a GBS vaccine $[4,12]$. In that case, the inclusion in a vaccine of both $\mathrm{c}^{\alpha}$ and $\mathrm{R} 4$ could, theoretically, provide protection to c. $90 \%$ of the population (Table 2).

In conclusion, the results of the present study have demonstrated that distribution of serotypes and serosubtypes among Zimbabwean GBS show considerable similarity to the distribution in GBS isolated in other parts of the world. However, some distinctive features of Zimbabwean GBS were noted, in particular regarding subtypes of type $\mathrm{V}$ isolates. PFGE demonstrated genomic heterogeneity of Zimbabwean type III/R4 and type $\mathrm{V} / \mathrm{c}^{\alpha}$, R3 GBS isolates but to a lesser extent than recorded with Norwegian isolates. The results of the serotype determination may be important as a basis for formulation of a GBS vaccine for Zimbabwe and possibly for other countries in the Southern and Central African region. 
We thank Kirsti Løseth, Randi V. Lyng and J. Mudzoiv for their technical assistance.

\section{References}

1. Stoll BJ, Schuchat A. Maternal carriage of group B streptococci in developing countries. Pediatr Infect Dis J 1998; 17: 499-503.

2. Nathoo KJ, Mason PR, Chimbira THK, and the Puerperal Sepsis Study Group. Neonatal septicaemia in Harare Hospital: aetiology and risk factors. Cent Afr J Med 1990; 36: 150-156.

3. Moyo SR, Mudzori J, Tswana SA, Maeland JA. Prevalence, capsular type distribution, anthropometric and obstetric factors of group B Streptococcus (Streptococcus agalactiae) colonization in pregnancy. Cent Afr J Med 2000; 46: 115-120.

4. Paoletti LC, Madoff LC, Kasper DL. Surface structures of group B Streptococcus important in human immunity. In: Fischetti VA, Novick RP, Ferretti JJ, Portnoy DA, Rood JI (eds) Gram-positive pathogens. Washington, DC, ASM Press. 2000: 137-153.

5. Bevanger L, Maeland JA. Complete and incomplete Ibc protein fraction in group B streptococci. Acta Pathol Microbiol Immunol Scand B 1979; 87B: 51-54.

6. Bevanger L, Iversen O-J, Naess AI. Characterization of the a antigen of the c proteins of group B streptococci (GBS) using a murine monoclonal antibody. APMIS 1992; 100: 57-62.

7. Lancefield RC, Perlmann GE. Preparation and properties of $\alpha$ protein ( $\mathrm{R}$ antigen) occurring in streptococci of group $\mathrm{A}$, type 28 and in certain streptococci of other serological groups. $J$ Exp Med 1952; 96: 83-97.

8. Wilkinson HW. Comparison of streptococcal R antigens. Appl Microbiol 1972; 24: 669-670.

9. Areschoug T, Stålhammar-Carlemalm M, Larsson C, Lindahl G. Group B streptococcal surface proteins as targets for protective antibodies: identification of two novel proteins in strains of serotype V. Infect Immun 1999; 67: 6350-6357.

10. Lachenauer CS, Creti R, Michel JL, Madoff LC. Mosaicism in the alpha-like protein genes of group B streptococci. Proc Natl Acad Sci USA 2000; 97: 9630-9635.

11. Lachenauer CS, Madoff LC. A protective surface protein from type $\mathrm{V}$ group $\mathrm{B}$ streptococci shares $\mathrm{N}$-terminal sequence homology with the alpha c protein. Infect Immun 1996; 64: 4255-4260.

12. Moyo SR, Maeland JA, Lyng RV. The putative R1 protein of Streptococcus agalactiae as serotype marker and as target of protective antibodies. APMIS 2001; 109: 842-848.

13. Stålhammar-Carlemalm M, Stenberg L, Lindahl G. Protein rib: a novel group B streptococcal cell surface protein that confers protective immunity and is expressed by most strains causing invasive infection. J Exp Med 1993; 177: 1593-1603.

14. Bevanger L, Kvam AI, Maeland JA. A Streptococcus agalactiae $\mathrm{R}$ protein analysed by polyclonal and monoclonal antibodies. APMIS 1995; 103: 731-736.

15. Nizet V, Rubens CE. Pathogenic mechanisms and virulence factors of group B streptococci. In: Fischetti VA, Novick RP, Ferretti JJ, Portnoy DA, Rood JI (eds) Gram-positive pathogens. Washington, DC, ASM Press. 2000: 125-136.

16. Bevanger L, Maeland JA. Type classification of group B streptococci by the fluorescent antibody test. Acta Pathol
Microbiol Immunol Scand B 1977; 85B: 357-362.

17. Moyo SR, Maeland JA, Bevanger L. Comparison of three different methods in monoclonal antibody-based detection of Streptococcus agalactiae serotype markers. APMIS 1999; 107: 263-269.

18. Naess AI, Bevanger L, Iversen O-J, Maeland JA. Evaluation of monoclonal antibodies in serovar classification of group B streptococci (GBS). APMIS 1991; 99: 1058-1060.

19. Kvam AI, Bevanger L, Maeland JA. Properties and distribution of the putative R3 protein of Streptococcus agalactiae. APMIS 1999; 107: 869-874.

20. Fasola E, Livdahl C, Ferrieri P. Molecular analysis of multiple isolates of the major serotypes of group B streptococci. J Clin Microbiol 1993; 31: 2616-2620.

21. Hordnes K, Tynning T, Kvam AI, Jonsson R, Haneberg B Colonization in the rectum and uterine cervix with group $\mathrm{B}$ streptococci may induce specific antibody responses in cervical secretions of pregnant women. Infect Immun 1996; 64: $1643-1652$.

22. Rossetti R, Maranini B, Soldi P. Vaginal colonization by Streptococcus agalactiae in two neighbouring populations in Tuscany. Adv Exp Med Biol 1997; 418: 249-250.

23. Regan JA, Klebanoff MA, Nugent RP et al. Colonization with group B streptococci in pregnancy and adverse outcome. Am J Obstet Gynecol 1996; 174: 1354-1360.

24. Suara RO, Adegbeola RA, Baker CJ, Secka O, Mulholland EK, Greenwood BM. Carriage of group B streptococci in pregnant Gambian mothers and their infants. J Infect Dis 1994; 170: 1316-1319.

25. Lachenauer CS, Kasper DL, Shimada J et al. Serotypes VI and VIII predominate among group B streptococci isolated from pregnant Japanese women. J Infect Dis 1999; 179: 1030-1033.

26. Ferrieri P, Flores AE. Surface protein expression in group B streptococcal invasive isolates. In: Horaud $\mathrm{T}$, Bouvet $\mathrm{A}$, Leclercq R, de Montclos H, Sicard M (eds) Streptococci and the host. New York, Plenum Press. 1997: 635-637.

27. Kvam AI, Efstratiou A, Bevanger L et al. Distribution of serovariants of group B streptococci in isolates from England and Norway. J Med Microbiol 1995; 42: 246-250.

28. Blumberg HM, Stephens DS, Modansky M et al. Invasive group B streptococcal disease: the emergence of serotype V. J Infect Dis 1996; 173: 365-373.

29. Harrison LH, Elliot JA, Dwyer DM et al. Serotype distribution of invasive group B streptococcal isolates in Maryland: implications for vaccine formulation. J Infect Dis 1998; 177: 998-1002.

30. Blumberg HM, Stephens DS, Licitra C et al. Molecular epidemiology of group B streptococcal infections: use of restriction endonuclease analysis of chromosomal DNA and DNA restriction fragment length polymorphisms of ribosomal RNA genes (ribotyping). J Infect Dis 1992; 166: 574-579.

31. Gordillo ME, Singh KV, Baker CJ, Murray BE. Typing of group B Streptococci: comparison of pulsed-field gel electrophoresis and conventional electrophoresis. J Clin Microbiol 1993; 31: $1430-1434$.

32. Rolland K, Marois C, Siquier V, Cattier B, Quentin R. Genetic features of Streptococcus agalactiae strains causing severe neonatal infections, as revealed by pulsed-field gel electrophoresis and hylB gene analysis. J Clin Microbiol 1999; 37: $1892-1898$. 